\title{
Harvey Cushing (1869-1939): Father of neurosurgery
}

\author{
Patrick $\underline{\operatorname{Pan}}^{1}, \mathrm{MD}$, Siang Yong $\underline{\operatorname{Tan}}^{2}, \mathrm{MD}, \mathrm{JD}$
}

If you are going for it, I certainly would go in for it hard. Half-way measures never got anybody anywhere. - Letter from Harvey Cushing to his son Bill regarding his son's intention to join the Yale varsity hockey team.

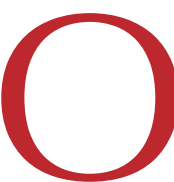

n a Saturday morning in 1926, Dr Harvey Cushing, chief and professor of surgery at Harvard's Peter Bent Brigham Hospital, operated meticulously on a young woman with a brain tumour. The three-hour long operation was successful, yet Cushing's stoic expression belied the turmoil and grief that raged within. He had just received news that his eldest son, Bill, was killed in an automobile accident. Known to many as the pioneer of American neurosurgery, Harvey Cushing was more than just a great surgeon. He once stated that "neurosurgery was 20\% science, $75 \%$ artistry, and 5\% community benefit". Indeed it was intensity, sensitivity and discipline - in essence characteristics of an artist - that truly personified this great man.

EARLY YEARS The youngest of ten children, Harvey Cushing was born in Cleveland, Ohio, USA in 1869. At a young age, he was

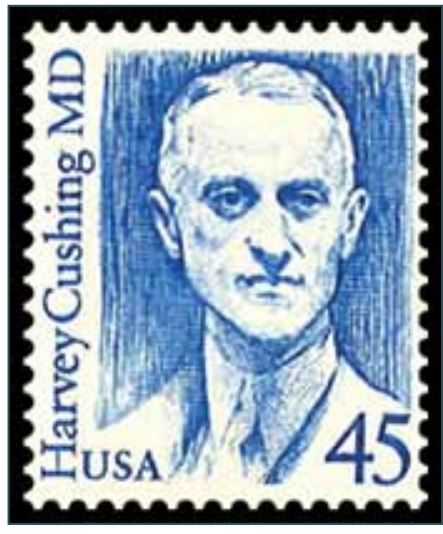

Kate Crowell, who was visiting Boston from his hometown of Cleveland. He continued to woo her throughout medical school and his residency at Johns Hopkins. Years passed, but Cushing was not quite ready to marry her, for he wanted "the house furnished and the carpets down and a warm fire burning for her". In reality, he insisted on putting his surgical training ahead of romance. They were eventually married in Cleveland in 1902. These early accounts of Cushing illustrate a determination that characterises his lifelong behaviour.

\section{ORIGINS OF NEUROSURGERY Although} operations on the brain had been attempted since ancient times, surgical interest in neurological problems in more modern times began only after the development of antisepsis and anaesthesia. The field of neurosurgery was ignited by operations in 1879 by William McEwen, and in 1884 by Alexander Bennot and Rickman Godlee. The latter published and demonstrated that a neurological examination could locate an intracranial tumour such that the precise spot could be marked and removed. From nicknamed 'Pepper Pot' because of his temper. Bright and destined to succeed as a fourth generation physician in the Cushing family, he learned wood and metal work and machinery before attending Yale University. He frequently misspelt words in his letters to his family, prompting his father to urge him to "please buy a dictionary and consult it as you write". Cushing was a good, but not outstanding, student and found time to excel in baseball and gymnastics. Upon graduation, he entered Harvard Medical School, although his talent and interest in drawing led him to consider architecture at one point. Two events during medical school significantly changed him. The first was the death of a patient to whom he had administered ether for anaesthesia. He was so distraught that he almost quit. However, instead of quitting, he and his classmate, Amory Codman, devised anaesthesia charts that measured the patient's pulse and respiration, an innovation that contributed to modern anaesthesiology and significantly reduced patient death from ether. Second, while at Harvard, Cushing fell in love with
1886 to 1896 , more than 500 general surgeons reported attempts at brain surgery. However, the actual surgery was much more difficult to perform than in theory. When Cushing finished his residency at Johns Hopkins, he travelled to Europe where he witnessed this crude procedure, in working out the presumable location and nature of... a cerebral tumor. An operator is called in; he has little knowledge of maladies of this nature and less interested in them, but is willing to undertake the exploration. The supposed site of the growth is marked out for him on the scalp by the neurologist; and he proceeds to trephine. The dura is opened hesitatingly; the cortex is exposed, and too often no tumor is found. The operator's interest ceases with the exploration, and for the patient the common sequel is a hernia, a fungus cerebri, meningitis, and death".

The high morbidity and mortality rates for brain surgery sapped the surgeon's enthusiasm. One researcher, John Scarff, noted that the number of surgical cases from 1896 described as follows: "The neurologist spends days or weeks

${ }^{1}$ Research carried out as a medical student, John A Burns School of Medicine, ${ }^{2}$ Emeritus Professor of Medicine, John A Burns School of Medicine, Honolulu, Hawaii, USA

Correspondence: Prof Tan Siang Yong, 2230 Liliha Street, Suite 104, Honolulu, HI 96817, USA. siang@hawaii.edu 
to 1906 had fallen to less than 80 , reflecting "discouragement and a beginning of return to sanity".

TACKLING NEUROSURGERY Cushing graduated from Harvard Medical School cum laude in June of 1895 and entered his internship at Massachusetts General Hospital. In the fall of 1896, Cushing arrived in Baltimore, where he began his general surgery residency under Dr William Halstead at the newly established Johns Hopkins University. From Halstead, Cushing learned delicate and conservative operating techniques, known as the Halstedian technique of surgery, which emphasises anatomic dissection, precise haemostasis and gentle tissue handling. This was the result of Halstead's compulsive attention to detail, notwithstanding his unfortunate addiction to cocaine. It was Halstead's unique surgical training programme and focus on research that Cushing built upon to develop his neurosurgical techniques.

It was also at Johns Hopkins that the 27-year-old Cushing met his mentor and lifelong friend, a 47-year-old professor of medicine named William Osler. As a medical student, Cushing had already known of Osler because he had studied from Osler's textbook. Both men got along well in their shared fondness for books. As a house officer at Johns Hopkins, Cushing was welcomed into the Osler household and given a latchkey that allowed him access to Osler's extensive medical library and pantry. At Osler's urging, Cushing travelled to Europe after completing his surgical residency in 1900, and worked with several famous surgeons and researchers of the time. In Bern, Switzerland, he worked in Theodor Kocher's laboratory, where he developed an understanding of intracranial pressure, which would eventually be known as Cushing's Reflex. In a letter to his fiancée, Kate, he wrote, "I've made a lucky find in some experimental work which won't make me famous, but will help me and some other people understand a little better some things about brain surgery". The year in Europe stoked his surgical passion, and when he returned to Johns Hopkins in October of 1901, Cushing informed Halstead that he intended to be the first to specialise exclusively in neurological surgery. It was a courageous decision. In the preceding ten years at Johns Hopkins, only 32 cases of brain tumours had been correctly diagnosed; two had been operated upon, but neither patient survived.

\section{PERFECTING NEUROSURGERY Harvey Cushing} kept to a furious and fastidious schedule, which included operating, giving lectures and working in the laboratory. At Johns Hopkins, he notably befriended the medical artist, Max Broedel, who inspired him to use his own artistic talents in recording his neurosurgical experiences. He kept detailed notes, complete with drawings after each operation, and sometimes wrote up to 10,000 words per day. He was indefatigable; when asked to contribute an 80-page chapter on surgery of the head to Keen's text 'Surgery', he submitted a manuscript of 800 pages, complete with more than 200 hand-drawn illustrations.

Cushing's early attempts at neurosurgery resulted in a dismal mortality rate of $95 \%$. However, his focused attention on controlling intracranial pressure eventually paid off. In 1905, the first publication of his efforts, 'The special field of neurological surgery', discussed his high-mortality technique, but by 1910 , the death rate had dropped to $13 \%$.

Cushing stayed at Johns Hopkins until 1912 when he moved to Harvard's newly built Peter Bent Brigham Hospital. There, he further refined neurosurgery and brought its mortality rate down to $8 \%$. Importantly, he founded the Society of Neurosurgeons and trained a generation of neurosurgeons from around the world. Meanwhile, he developed a theatrical sense, especially in the presence of visiting surgeons, adding flair to accompany his infamous temper during surgery.

A FINAL CHALLENGE When William Osler died in December of 1919, Osler's widow urged Cushing to write the biography of the man he considered his spiritual father. In the summer of 1920, Cushing began his research, first spending six weeks at Osler's home in Oxford. The book, titled 'The Life of Sir William Osler', took four years to complete and encompassed two thick volumes. It was a resounding success that won the Pulitzer Prize in biography - a fitting prelude to the final chapter of a man whose dogged determination laid the foundations for modern neurosurgery. When the rigors from years of performing operations, a bout of Guillain Barré from which he never fully recovered, and claudication in his legs began to take their toll, Cushing returned to Yale to spend time with family, friends and students. He reportedly mellowed into a "very kind, gentle and fatherly" man in his final years.

\section{BIBLIOGRAPHY}

- Black PM. Harvey Cushing at the Peter Bent Brigham Hospital. Neurosurgery 1999; 45:990-1001.

- Bliss M. Harvey Cushing: A life in Surgery. New York: Oxford University Press, 2005.

- Cushing $\mathrm{H}$. The special field of neurological surgery. Bulletin of the Johns Hopkins Hospital 1905; 16:77-87. Reprinted in Neurosurgery 2005; 57:1075.

- Davey LM. Harvey Cushing: the New Haven years. Neurosurgery 1999; 45:1002-9.

- Duffy TP. The Osler-Cushing covenant. Perspect Biol Med 2005; 48:592-602.

- Greenblatt SH. Harvey Cushing's paradigmatic contribution to neurosurgery and the evolution of his thoughts about specialization. Bull Hist Med 2003; 77:789-822.

- Kutz S, O'Leary JP. Harvey Cushing: a historical vignette. Am Surg 2000; 66:801-3.

- Long DM. Harvey Cushing at Johns Hopkins. Neurosurgery 1999; 45:983-9.

- Young AB. Scalpel: Men Who Made Surgery. New York: Random House, 1956. 